\title{
REVIEW
}

\section{Pediatric Ulcerative Colitis: The Therapeutic Road to Infliximab}

Pamela R. Puthoor $\cdot$ Edwin F. de Zoeten

To view enhanced content go to www.biologicstherapy-open.com

Received: September 12, 2012 / Published online: January 4, 2013

(c) The Author(s) 2012. This article is published with open access at Springerlink.com

\begin{abstract}
Ulcerative colitis (UC) is a chronic inflammatory bowel disease that has significant morbidities in the pediatric population. Goals of medical therapy include induction and maintenance of remission while preserving the colon and it's function, while minimizing the risk of treatment related morbidities. For those children who do not respond to initial therapies and progress to develop moderately-to-severely active UC, there has been a dearth of available treatments to help induce remission, necessitating long-term corticosteroid usage, with associated comorbidities of chronic steroid treatment.
\end{abstract}

P. R. Puthoor · E. F. de Zoeten $(\bowtie)$

University of Colorado Denver School of Medicine, Department of Pediatrics, Children's Hospital Colorado, Digestive Health Institute, Anschutz Medical Campus, 13123 East 16th Avenue, B290, Denver, USA

e-mail: Edwin.DeZoeten@childrenscolorado.org

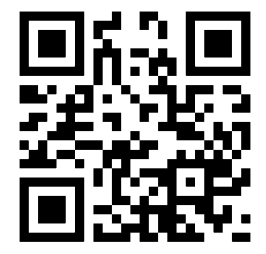

Enhanced content for this article is available on the journal web site: www.biologicstherapy-open.com
Significant advances have been made in medical management, including the use of biologic therapies, specifically anti-tumor necrosis factor- $\alpha$ monoclonal antibodies. With the Food and Drug Administration's recent approval of the use of infliximab, a chimeric anti-tumor necrosis factor- $\alpha$ antibody, for children $\geq 6$ years of age with moderately-toseverely active UC, care providers now have a new treatment regimen to offer this pediatric population.

Keywords: Gastroenterology; Infliximab; Pediatric; Tumor necrosis factor- $\alpha$; Ulcerative colitis

\section{INTRODUCTION}

Ulcerative colitis (UC), along with Crohn's disease (CD) and inflammatory bowel disease undetermined type (IBDU) make up the spectrum of inflammatory bowel diseases (IBD). IBD affects thousands of children worldwide [1-4]. The highest incidence occurs in developed industrialized countries, with 2-7 children per 100,000 becoming affected each 
year in the USA $[3,5]$. IBD is a destructive chronic inflammatory condition of the gastrointestinal (GI) tract, and thus far the etiology remains poorly understood, although numerous studies point to a combination of genetic, environmental, and host factors. Current hypotheses of the pathogenesis of IBD suggest that pathogenic or normal enteric flora provide antigenic stimulation leading to a dysregulated immune response in genetically susceptible individuals with multiple potential environmental predisposing factors causing tissue damage and disease pathology [6-9]. In this review, the authors will discuss current therapies in pediatric UC, with a focus on the indications for and the use of infliximab in treating children with moderately-to-severely active UC.

\section{PATHOPHYSIOLOGY OF UC}

While much of the etiology of IBD remains undetermined, the altered balance between enteric flora and the intestinal immune response in genetically susceptible individuals has been well described [10, 11]. Luminal antigens interact with the mucosa normally, yet with increased permeability one sees triggering of multiple inflammatory pathways, including the innate and adaptive immune systems [12]. In UC, in response to bacterial lipopolysaccharides, the $\mathrm{T}$ helper 2 (Th2) response produces cytokines, interleukin (IL)-5, and IL-13, as well as other proinflammatory cytokines, which induce macrophages, monocytes, neutrophils, $\mathrm{T}$ cells, and natural killer (NK) cells to secrete tumor necrosis factor$\alpha$ (TNF- $\alpha)$, IL-1, and IL-6 [10, 11, 13]. TNF- $\alpha$ activates leukocytes, induces acute phase reactants, and inhibits apoptosis of inflammatory cells, and can be found in significant amounts in the mucosa of patients with active UC [14]. Leukocytes migrate into the mucosa, and release proteases, nitric oxide, prostaglandins, free oxygen radicals, endopeptidases, and chemokines which both directly damage tissue and further amplify the inflammatory process [11]. Understanding the etiology of UC has guided the development of treatment for the disease and the approach to this illness.

The complex dysregulated immune response along with severe inflammation lead to the key feature of UC: diffuse superficial mucosal inflammation extending proximally from the rectum to varying locations [10]. The affected area of the colon is variable and can affect anywhere from the distal sigmoid alone, to pancolitis. As compared with adults, the pediatric UC population tend to present with more extensive colonic involvement and more commonly present with moderate-to-severe disease activity [15].

Pediatric UC patients commonly present with hematochezia, diarrhea, and abdominal pain. Diagnostic evaluation consists of a detailed history, physical exam, laboratory data, small bowel imaging, upper GI endoscopy, and colonoscopy. While pediatric UC is limited to colonic inflammation, upper endoscopy is key in evaluating for signs of CD. Histologic findings are essential in confirming the diagnosis of $\mathrm{UC}$, and include colonic mucosal inflammation, crypt distortion, crypt microabscesses, and goblet cell depletion [16].

\section{Role of TNF- $\alpha$ in UC}

TNF- $\alpha$, produced by activated macrophages and $\mathrm{T}$ lymphocytes, is a key proinflammatory cytokine in IBD. TNF- $\alpha$ has multiple actions, including: (1) inducing many other proinflammatory cytokines, including IL-1, IL-6, 
and IL-8; (2) enhancing leukocyte migration by increasing expression of adhesion molecules by endothelial cells; (3) activating leukocytes; (4) inhibiting inflammatory cell apoptosis; and (5) inhibiting regulatory macrophages which have suppressive effects on the immune system, including inhibiting the proliferation of activated $\mathrm{T}$ cells [17-19]. TNF- $\alpha$ has been found in increased amounts in the mucosa of patients with UC [14].

\section{Clinical Scoring of UC}

Defining the severity of disease activity is imperative in determining a treatment approach. The moderate-to-severe phenotype is a common presentation in children, with $>80 \%$ of children presenting with macroscopic inflammation beyond the splenic flexure, as compared to less than half of adults with disease limited to the rectosigmoid [20]. While there is a paucity of data on the frequency of severe UC exacerbation in children, reported data on the prevalence of severe UC at diagnosis varies from 15 to $57 \%$. In pediatrics, use of the validated Pediatric Ulcerative Colitis Activity Index (PUCAI) based on clinical symptom reporting, is useful in stratifying disease severity, in which a PUCAI score of at least 65 was highly associated with physician global assessment of severe disease (sensitivity 92\%, specificity 94\%) $[21,22]$. Prospective data has supported the use of PUCAI scoring in helping gauge treatment decisions. Using this system, approximately one-third of children with moderate-to-severe PUCAI scores requiring hospital admission and intravenous (IV) steroids will fail IV steroids, and go on to require more intensive therapies. Of those children who responded to IV steroids, most responded within 6 days of therapy [23].

At this time, accepted definitions of moderate-to-severe colitis can be determined by using a combination of clinical history, exam, need for hospitalization, and PUCAI scoring, in which a score of moderate (35-64 points) or severe ( $\geq 65$ points), and response to IV steroid therapy, where PUCAI scores on day 3 and 5 of treatment can be predictive of treatment failure. If PUCAI scores do not improve ( $>45$ points) by day 3 of therapy, discussions surrounding second-line therapy should be initiated [24].

\section{CURRENT THERAPIES}

Treatment paradigms for UC have centered on inducing and maintaining disease remission, in order to improve clinical symptoms and promote mucosal healing, thus promoting improved growth, nutrition, and quality of life. Various diagnostic and treatment algorithms have been developed from the assessment and treatment of UC, although it remains medically incurable. There is a general paucity of evidence in treating children with IBD, thus many treatment modalities have been based on adult data [25]. Inducing remission is initiated with a combination of antiinflammatory medications and possibly corticosteroids, with the goal of minimizing medication use and steroid exposure [26].

Treatment focuses on addressing disease severity and initiating the corresponding agent to appropriately treat symptoms while avoiding adverse reactions associated with other therapies. Treatment options are varied, including 5-aminosalicylates (5-ASA), corticosteroids, 6-mercaptopurine (6-MP), antibiotics, surgery, and most recently, antiTNF- $\alpha$ monoclonal antibody therapy. Therapies used prior to the introduction of anti-TNF- $\alpha$ (discussed in detail in the following section), left an unmet need for those with more severe disease. Anti-TNF- $\alpha$ monoclonal antibodies 
have helped to address the unmet medical need in patients with moderate-to-severe UC who are steroid-resistant or dependent and in whom immuno modulators are not successful in achieving remission.

Dosing and treatment approach in using these myriads of medications is varied and there is significantly less data to support the use of these therapies in children as compared to adults. There are strong data to support the use of 5-ASA as initial therapy in mild-tomoderate UC [27]. The mechanism of action of 5-ASA remains unclear, although the primary effect is considered to be an anti-inflammatory effect directly on the mucosa, and as such is available in multiple formulations, including oral and rectal preparations (for more direct administration of disease limited to proctitis or distal left-sided disease) [28, 29]. While there have been minimal data on inducing and maintaining remission in pediatric UC, the data are strong in adult UC for both inducing remission, with number needed to treat estimated at 5, with $40 \%$ of patients achieving disease remission versus $20 \%$ with placebo, as well as preventing relapse, with $40 \%$ of patients on 5-ASA therapies relapsing versus 63\% relapsing on placebo $[25,30]$.

Corticosteroid therapy has been a mainstay of treatment of UC and symptomatic management, although it has been well established that corticosteroids do not promote mucosal healing [31, 32]. However, up to a third of children with UC will require corticosteroids to achieve disease remission at the time of diagnosis, one-fifth will become steroid dependent, and an additional one-third will require surgery [33]. In patients with no or partial response to oral, rectal, or topical corticosteroids, treatment often escalates to inpatient admission and IV steroid therapy $[28,33,34]$. As noted above, in those who fail
IV steroid therapy, second-line therapy must be considered. In adults, both IV cyclosporine and oral tacrolimus have also been shown to be effective at inducing remission in IV steroid failure [35-38]. The use of IV cyclosporine has not been as successful in small pediatric cohort studies, which demonstrated short benefit with the use of cyclosporine with successful delay of colectomy of $81 \%$ of patients in the acute period, but only 39\% avoided colectomy at long-term follow-up; and thus with its significant side effect profile including nephrotoxicity, it is not indicated in maintaining remission [24, 39].

The role of immunomodulators, including 6-MP and its prodrug azathioprine, has been indicated in maintaining remission of disease. In a prospective cohort study, at 12-month followup of 133 patients receiving a thiopurine immunomodulator, $49 \%$ had steroid-free inactive disease without the need for escalating therapies, and an additional $10 \%$ had steroid-free mild disease [40]. The use of these therapies must be closely monitored, including a thiopurine methyltransferase (TPMT) enzyme level, which metabolizes 6-MP to its active metabolites 6-thioguanine nucleotide (6-TGN) and 6-methylmercaptopurine (6-MMP), where increased levels of 6-TGN have been associated with a favorable therapeutic response, and increased levels of 6-MMP have been associated with increased hepatotoxicity. Indeed, the adverse reactions associated with immunomodulators, including allergic reactions, myelosuppression, hepatotoxicity, and malignancy (including lymphoma) have been well described as both dose dependent effects (myelosuppression, hepatotoxicity) as well as idiosyncratic, regardless of treatment dosing [41].

Surgical therapy remains the only potentially curative treatment in UC, and is considered a 
final option for recalcitrant cases that fail higher-tier medical therapies. Indications for emergent surgical therapy include those patients who present with severe symptomatology, including perforation, persistent bleeding, anemia, and toxic megacolon [42]. Elective surgery should be considered in those with refractory disease, signs of colonic dysplasia or rectal cancer, or those who chose to decline biologic therapy [43]. The most widely accepted surgical technique includes a total proctocolectomy with ileal j-pouch anal anastomosis, generally staged with a temporizing diverting ileostomy. Surgery is not without complications, including increased risks of pouchitis, increased stooling frequency, incontinence, reduced fertility, need for surgical revision or reoperation, and pouch failure. Reported failure rates in adults range from 6.8 to $8.5 \%$ at $36-60$ months post colectomy [44]. Although surgical intervention can be potentially curative for UC, achieving sustained clinical remission while preserving the colon is the optimal successful outcome. Anti-TNF- $\alpha$ antibody agents offer an opportunity to avoid colectomy.

\section{INFLIXIMAB}

Infliximab is a chimeric murine-human monoclonal immunoglobulin G1 antibody composed of a murine variable region linked to a human constant region, and is produced by cell culture using Chinese hamster ovary cells [45-47]. Infliximab is administered IV and remains in the extracellular fluid, binding to human TNF- $\alpha$ with high affinity and inducing apoptosis of $T$ cells and monocytes [48]. It has an approximate half-life of 10 days and with a single $5 \mathrm{mg} / \mathrm{kg}$ dose, levels are no longer detectable $\quad(<0.1 \mu \mathrm{g} / \mathrm{mL}) \quad$ by 12 weeks postinfusion. The effect on inflammatory cytokines can be rapid, with normalization of IL-6 levels within 2 weeks of therapy $[46,49]$.

\section{The Use of Infliximab in Treating UC: Adult Data}

Data on infliximab's use in adult UC came shortly after the US Food and Drug Administration (FDA) approval of infliximab for CD in 1998. To date, there have been five randomized control trials (RCT) reporting efficacy of biologic therapies in inducing remission in adult patients with moderatelyto-severely active UC who failed corticosteroid therapy. The first combined trials, the Active Ulcerative Colitis Trials 1 and 2 (ACT 1 and ACT 2, respectively), evaluated the efficacy of infliximab in 364 adults with moderately-toseverely active UC versus placebo, in which patients had infliximab induction and maintenance therapy with longitudinal followup, where ACT 1 treated patients for 46 weeks with a total follow-up of 54 weeks, and ACT 2 treated and followed patients for a shorter duration (22 weeks of treatment, 30-week follow-up). Patients were followed by clinical symptoms, physician global assessment, and endoscopic findings, and in both studies those receiving infliximab had significant clinical responses to treatment as compared to placebo with $61.5-69.4 \%$ clinical improvement or remission versus $37 \%$ in ACT 1 , with similar rates in ACT 2. Longitudinal follow-up also showed a significantly higher sustained response in the treatment subjects of both studies. Importantly, mucosal healing at weeks 8,30 , and 54 (week 54 data from ACT 1 only) demonstrated significantly more patients with healing in the infliximab group [50].

In pooled data of adult RCTs of 827 patients in the inpatient and ambulatory setting, remission was achieved in over half the 
patients receiving infliximab (57.1\%) as compared to one-third of patients in the placebo cohort. Infliximab was also found to be efficacious, with a number needed to treat of 4 to achieve remission in one patient with moderately-to-severely active UC (95\% confidence interval [CI], 3-8) [50-54]. Although the ACT 1 and ACT 2 trials followed patients beyond the course of therapy, there have been no RCTs examining the use of biological therapies versus placebo in preventing relapse in quiescent UC [51].

\section{The Use of Infliximab in Treating UC: Pediatric Data}

Since the early 2000s, there has been a growing body of data based on open label use of infliximab to support its use in treating the pediatric population with moderate-to-severe UC. Here, the authors review the data leading to the FDA's approval of infliximab for use in pediatric UC in September 2011. Data for this review is derived from PubMed listed literature describing both retrospective and prospective studies of infliximab use in children $<18$ years of age with UC. The authors excluded literature from single case reports or case series.

Overall, the data have been supportive for the use of infliximab in the pediatric UC population for improving clinical symptoms and for some, achieving disease remission, with evidence of endoscopic healing [55-64]. Seminal studies addressing the use of infliximab for the treatment of UC are summarized in Table 1 [56-64]. This was initially found as part of treating a generalized cohort of pediatric patients with IBD [55]. In 2002 and 2004, Mamula et al. [56, 57] reported on a larger cohort of children with UC who were persistently symptomatic after 2 weeks of corticosteroids (nine patients in total), all of whom had pancolitis at the initiation of therapy. Seven patients demonstrated significant clinical improvement after just 2 weeks of therapy, and of these seven patients, six had improved to clinically inactive disease. For those whom infliximab did not induce improvement, one went on to colectomy, and the other resumed corticosteroid therapy [56]. In longitudinal follow-up of this cohort, of the original seven patients with clinical response, five achieved sustained remission (including three subjects who maintained remission after discontinuation of therapy for up to 22 months at the time of data collection), while two went on to colectomy. They gained eight new subjects in the interim, seven of whom had also experienced clinical improvement on infliximab [57].

Russell and Katz [58] performed a retrospective cohort study, and noted that when stratifying children with moderately-toseverely active UC, children who were newly diagnosed or who relapsed off steroids tended to respond to infliximab, while those who were steroid dependent did not have as strong a clinical response. This retrospective review was limited by small cohort sizes [58]. Follow-up data from the same investigators in 27 patients stratified by acute or chronic disease again found higher rates of success in achieving disease remission in those with acute disease versus chronic disease $(75 \%$ vs. $27 \%$, respectively) [60]. This was not corroborated in the data presented by Eidelwein et al. [59], in which a cohort of 12 patients, including those with steroid-refractory fulminant colitis $(n=3)$ and steroid dependent colitis $(n=9)$ received infliximab, and all patients responded (three patients partially, nine patients with complete remission).

With the promising data on infliximab, larger cohort studies have further supported its 


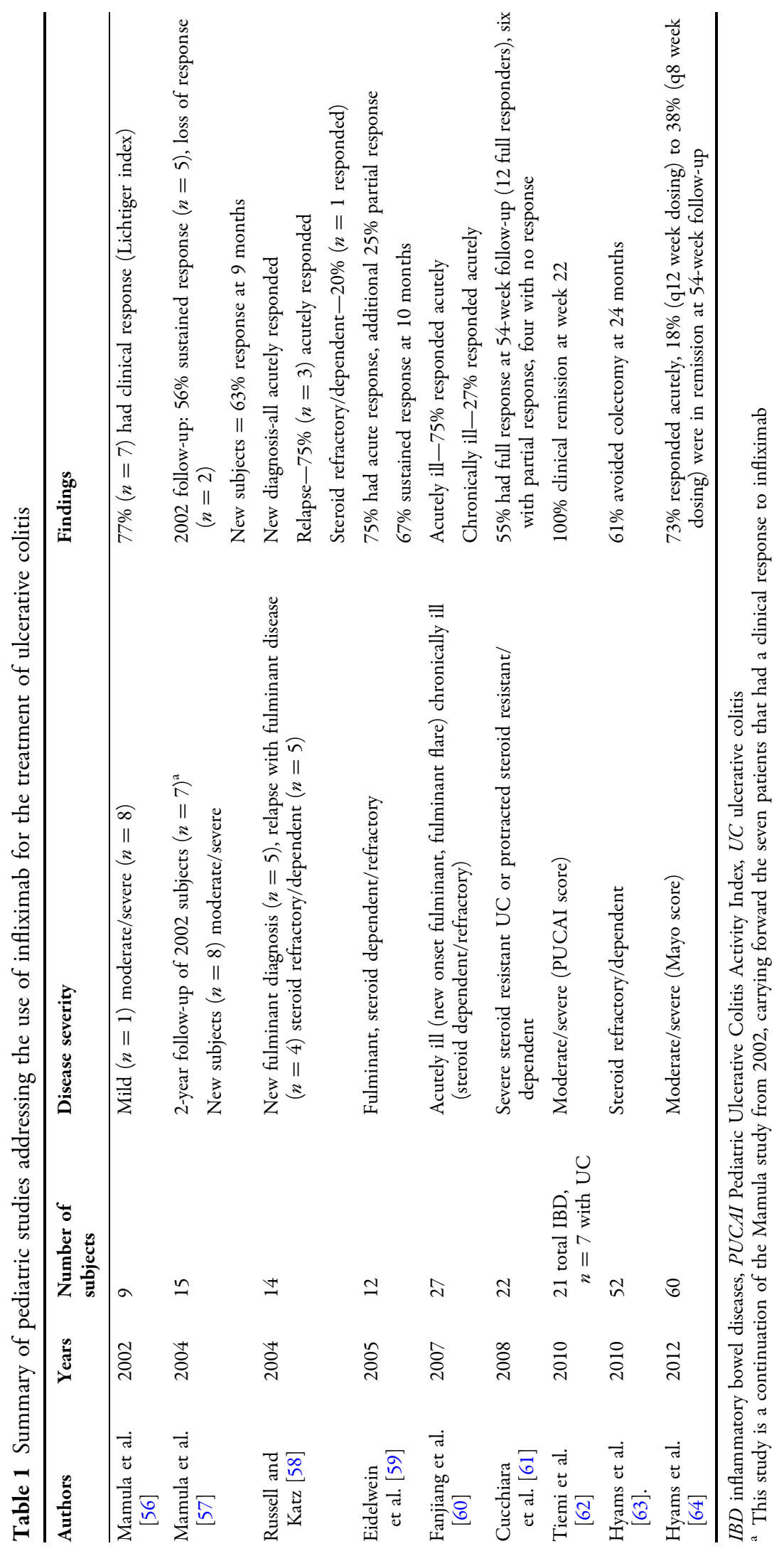


use for this refractory population. McGinnis and Murray [65] published on a large cohort of 40 patients, using the adult clinical scoring system by Truelove and Witt [66], in which they demonstrated that $70 \%$ of patients with moderate-to-severe UC identified clinical response and, importantly, that at long-term follow-up (median 19 months) those who initially responded to infliximab had much lower rates of colectomy versus those who did not respond ( $20 \%$ colectomy rate vs. $82 \%)$ $[65,66]$.

Cucchiara et al. [61] had a larger cohort of patients maintained on infliximab beyond the initial induction phase of $6-8$ weeks. In their cohort of 22 patients, 12 patients acutely responded to infliximab, eight of whom went on to receive infliximab routinely every 8 weeks, while the remaining four went on to receive azathioprine alone. Follow-up at 54 weeks found that both groups remained in clinical remission [61]. These findings warrant further examination for the clinical utility in infliximab maintaining remission, for which data is lacking in both adult and pediatric populations [30].

Hyams et al. [63] corroborated the above data with data from the Pediatric Inflammatory Bowel Disease Collaborative Research Group Registry, a multicenter consortium of 21 IBD centers in the United States and Canada. In their cohort of 52 patients, a majority of which had moderately-to-severely active UC (84\%), a significant proportion responded to infliximab (36\% with inactive disease, 19\% with mild disease after treatment), although a portion of those patients remained on corticosteroids; as to whether these were being tapered or maintained for disease activity is unknown. On longitudinal follow-up, those who remained with inactive and mild disease decreased to 21 and $11 \%$, respectively, with a cumulative colectomy rate of 16 . It is difficult to extrapolate whether this loss of sustained response was secondary to infliximab, as a majority of patients remained on infliximab therapies for varying lengths of time [63]. Longitudinal use of infliximab was more clearly studied in patients with a response to acute infliximab therapy (44 of 60 patients) who were randomized to receive infliximab every 8 or 12 weeks. Follow-up at 54 weeks indicated that there were more subjects in remission in the cohort who received infliximab every 8 weeks (8 of 22 patients) versus 12-week dosing (4 of 22 patients), with an overall remission rate of $28.6 \%$ [64]. These data were supported by Turner et al., who noted that in a cohort of 33 patients who received infliximab, at 1-year follow-up, $52 \%$ of those who initially responded to infliximab remained in remission [23].

Taken together, the available pediatric literature supports the use of anti-TNF- $\alpha$ medications in the treatment of UC. Most recently, this data was supported by Consensus Guidelines for the Management of Pediatric Ulcerative Colitis by the European Crohn's and Colitis Organization (ECCO) and the European Society for Paediatric Gastroenterology, Hepatology and Nutrition (ESPGHAN) [67]. In fact, in 2011, the FDA approved infliximab for the treatment of moderately-to-severely active UC in children $>6$ years of age in the setting of inadequate response to conventional therapy. The infliximab dose used in pediatric patients is $5 \mathrm{mg} / \mathrm{kg}$. Similar to the adult population, IV infusions are given at 0,2 , and 6 weeks for induction. Infusions are then administered every 8 weeks for maintenance of remission. However, when there is inadequate response, especially in the setting of sub therapeutic infliximab trough levels, the dosage may be 
increased (up to $10 \mathrm{mg} / \mathrm{kg}$ ) or the dosing interval may be decreased.

\section{Immunogenicity of Infliximab}

A well-described phenomenon in the use of monoclonal antibody therapy is the antigenic potential of the antibody to elicit a host immune response against the treatment, known as immunogenicity. In the case of infliximab, this potential for developing human anti chimeric antibodies (HACA) and thereby having accelerated degradation of infliximab is a potential explanation for those who develop a loss of therapeutic response, lack of response, and infusion reactions [68-70]. Giving regularly scheduled dosing and the concomitant use of immunomodulators can help ameliorate this response $[68,71]$. There is a commercially available test, Anser ${ }^{\mathrm{TM}}$ IFX (Prometheus Laboratories Inc., San Diego, CA, USA) that can measure both HACA levels and infliximab levels, and can be drawn at any time during the therapeutic regimen, although currently this is not widely in use in clinical practice.

\section{Adverse Reactions with Infliximab Therapy}

Potential issues regarding the blocking of TNF- $\alpha$ can include severe opportunistic infections, malignancy, severe anaphylaxis, and mortality [72]. In ACT 1 and ACT 2, no statistically significant difference was found in patients experiencing infusion reactions or other common adverse effects, including headache, rash, or arthralgia [50-54]. A recent review by Lichtenstein et al. [72] on adult data noted an increased risk of any infection (50.1\% vs. $36.3 \%$ in placebo, $P<0.001$ ), but no difference in the frequency of serious infection $(5.4 \%$ vs. $2.4 \%$,
$P=0.085)$, with no difference in the risk of infection if the patient was concomitantly on an immunomodulator. There was no difference in the risk of malignancy or mortality [72]. In a small single center study from Finland $(n=23)$, adverse reaction rates were reported as $26 \%$, including abscess at infusion site, anaphylaxis, urticaria, dizziness, and nausea, chest pain, and severe sepsis with multifocal leukoencephalopathy in a 16-year-old male which resolved within 6 months of discontinuation of therapy [73]. However, in the aforementioned studies, only two patients were reported as having to discontinue therapy, a minority requiring treatment with acetaminophen and diphenhydramine and a minority with transient symptoms of flushing, dizziness, pruritis, and tachycardia which resolved spontaneously [56-60]. Two reported patients required antibiotics; one received oral therapy for an upper respiratory infection, the other required IV antibiotic therapy for a local cellulitis at the injection site [65].

Finally, concerns have been raised regarding increased risks of malignancies in children on anti-TNF- $\alpha$ therapy, including leukemia, Hodgkin's and non-Hodgkin's lymphoma, hepatosplenic $\mathrm{T}$ cell lymphoma (HSTCL), melanoma, and solid organ tumors, with 48 cases reported from a database search of the FDA's Adverse Event Reporting System [74]. Upon further investigation of risk factors associated with developing HSTCL, it was mainly associated with young males who had been exposed to both anti-TNF- $\alpha$ antibody therapy and thiopurine immunomodulators [75]. The authors did not find any association with HSTCL in patients who had received antiTNF- $\alpha$ antibody therapy alone, implying that TNF- $\alpha$ blockade alone may be necessary but not sufficient to lead to malignancy. At this time, there does appear to be an increased risk of 
malignancy associated with anti-TNF- $\alpha$ therapy but the low incidence reported does not preclude the use of this therapy for treating IBD; however, the body of data continues to grow.

Based on adult and pediatric data, while the use of infliximab must be monitored carefully for risks of infusion reactions or anaphylaxis and possible infection, overall it appears to be a safe therapy for use in the pediatric population.

\section{OTHER ANTI-TNF-A AGENTS}

There are currently multiple other anti-TNF- $\alpha$ agents on the market for the treatment of CD. Two of these include adalimumab, a fully human monoclonal antibody against TNF- $\alpha$ and certolizumab pegol, a pegylated Fab fragment of a humanized anti-TNF- $\alpha$ monoclonal antibody. While there is no current randomized, controlled pediatric trial in the treatment of UC with either biologic therapy, there are adult studies on the use of adalimumab, although it is currently not FDA approved for this indication. Sandborn et al. [76] evaluated the efficacy of adalimumab in adult patients with UC. In a controlled and double-blinded study they found adalimumab to be safe and more effective than placebo for the induction and maintenance of remission in patients with moderate-to-severe UC refractory to conventional therapy. There is one small, retrospective study of ten pediatric patients with IBD treated with adalimumab due to a lack or loss of response to infliximab. In this study, three patients with UC achieved improvement in the short term [77]. However, one of these patients later failed adalimumab treatment and required colectomy. This study included a very small number of UC subjects and larger studies are required to determine the efficacy of adalimumab in pediatric UC. There is promising data on adalimumab's use in pediatric Crohn's disease for patients with refractory disease, with loss of response or an adverse reaction to infliximab, with clinical remission rates reported between 22 and $42 \%[78,79]$. To date, there are no reports on the use of certolizumab pegol in the treatment of pediatric UC.

\section{CONCLUSION}

Infliximab has now been in use for over 10 years as therapy in IBD and the supporting body of data for its use in the pediatric population continues to grow.

While nonbiologic therapies for pediatric UC have been successful in managing children with mild disease, there has been a dearth of nonsurgical options to offer families. Infliximab is a promising option, and the authors encourage care providers to consider this in treating children with moderate-tosevere UC who are refractory to nonbiologic therapies and potentially delaying surgical intervention. With the FDA approval of infliximab use in UC in children $>6$ years of age, the authors hope the supporting evidence will continue to grow. At this time, the use of infliximab should be reserved for patients with moderately-to-severely active colitis that are either steroid dependent or resistant.

\section{ACKNOWLEDGMENTS}

Prior to peer review, Janssen Biotech was offered the opportunity to review this paper for scientific accuracy. No writing assistance, other editorial involvement, or financial support was provided by the manufacturer in the production of this manuscript. This article does not necessarily reflect the opinions, policies, or recommendations of Janssen Biotech or any of its employees. Dr. de Zoeten is the guarantor for 
this article, and takes responsibility for the integrity of the work as a whole.

Conflict of interest. The authors have no personal, commercial, academic, or financial conflicts of interest to declare. There was no funding or sponsorship received in relation to this paper.

Open Access. This article is distributed under the terms of the Creative Commons Attribution Noncommercial License which permits any noncommercial use, distribution, and reproduction in any medium, provided the original author(s) and the source are credited.

\section{REFERENCES}

1. Braegger CP, Ballabeni $P$, Rogler D, Vavricka SR, Friedt M, Pittet V. Epidemiology of inflammatory bowel disease: is there a shift towards onset at a younger age? J Pediatr Gastroenterol Nutr. 2011;53:141-4.

2. Gismera CS, Aladren BS. Inflammatory bowel diseases: a disease(s) of modern times? Is incidence still increasing? World J Gastroenterol. 2008;14:5491-8.

3. Kugathasan S, Judd RH, Hoffmann RG, et al. Epidemiologic and clinical characteristics of children with newly diagnosed inflammatory bowel disease in Wisconsin: a statewide population-based study. J Pediatr. 2003;143:525-31.

4. Lakatos PL. Recent trends in the epidemiology of inflammatory bowel diseases: up or down? World J Gastroenterol. 2006;12:6102-8.

5. Lashner BA. Epidemiology of inflammatory bowel disease. Gastroenterol Clin N Am. 1995;24:467-74.

6. Sartor RB. Microbial influences in inflammatory bowel diseases. Gastroenterology. 2008;134:577-94.

7. Sartor RB. Innate immunity in the pathogenesis and therapy of IBD. J Gastroenterol. 2003;38:43-7.

8. Kim SC, Ferry GD. Inflammatory bowel diseases in pediatric and adolescent patients: clinical, therapeutic, and psychosocial considerations. Gastroenterology. 2004;126:1550-60.
9. Mayer L. Current concepts of inflammatory bowel disease: etiology and pathogenesis, 5th ed. In: Kirsner JB, editor. Inflammatory bowel disease. 5th ed. Philadelphia: Saunders; 2000. p. 280-96.

10. Xavier RJ, Podolsky DK. Unravelling the pathogenesis of inflammatory bowel disease. Nature. 2007;448:427-34.

11. Baumgart DC, Carding SR. Inflammatory bowel disease: cause and immunobiology. Lancet. 2007;369:1627-40.

12. Soderholm JD, Olaison G, Peterson $\mathrm{KH}$, et al. Augmented increase in tight junction permeability by luminal stimuli in the non-inflamed ileum of Crohn's disease. Gut. 2002;50:307-13.

13. de Zoeten EF, Fuss IJ. Pediatric inflammatory bowel disease, 1st edn. In: Mamula P, Markowitz J, Baldassano RN, editors. New York: Springer; 2008. pp. 31-41.

14. Tsukada Y, Nakamura T, Iimura M, Iizuka BE, Hayashi N. Cytokine profile in colonic mucosa of ulcerative colitis correlates with disease activity and response to granulocytapheresis. Am J Gastroenterol. 2002;97:2820-8.

15. Hyams JS, Davis P, Grancher K, Lerer T, Justinich CJ, Markowitz J. Clinical outcome of ulcerative colitis in children. J Pediatr. 1996;129:81-8.

16. Russo P. Pediatric inflammatory bowel disease, 1st edn. In: Mamula P, Markowitz J, Baldassano RN, editors. New York: Springer; 2008. pp. 241-62.

17. Rutgeerts P, Van Assche G, Vermeire S. Review article: infliximab therapy for inflammatory bowel disease-seven years on. Aliment Pharmacol Ther. 2006;23:451-63.

18. Vos AC, Wildenberg ME, Duijvestein M, Verhaar $\mathrm{AP}$, van den Brink GR, Hommes DW. Anti-tumor necrosis factor-alpha antibodies induce regulatory macrophages in an Fc region-dependent manner. Gastroenterology. 2011;140:221-30.

19. Smolen JS, Emery P. Infliximab: 12 years of experience. Arthritis Res Ther. 2011;13(Suppl. 1):S2.

20. Van Limbergen J, Russell RK, Drummond HE, et al. Definition of phenotypic characteristics of childhood-onset inflammatory bowel disease. Gastroenterology. 2008;135:1114-22.

21. Turner D, Otley AR, Mack D, et al. Development, validation, and evaluation of a pediatric ulcerative colitis activity index: a prospective multicenter study. Gastroenterology. 2007;133:423-32. 
22. Turner D, Hyams J, Markowitz J, et al. Appraisal of the pediatric ulcerative colitis activity index (PUCAI). Inflamm Bowel Dis. 2009;15:1218-23.

23. Turner D, Mack D, Leleiko N, et al. Severe pediatric ulcerative colitis: a prospective multicenter study of outcomes and predictors of response. Gastroenterology. 2012;138:2282-91.

24. Turner D, Griffiths AM. Acute severe ulcerative colitis in children: a systematic review. Inflamm Bowel Dis. 2011;17:440-9.

25. Wilson D, Thomas A, Croft N, et al. Systematic review of the evidence base for the medical treatment of paediatric inflammatory bowel disease. J Pediatr Gastroenterol Nutr. 2010;50:S14-34.

26. Baumgart DC, Sandborn WJ. Inflammatory bowel disease: clinical aspects and established and evolving therapies. Lancet. 2007;369:1641-57.

27. Nielsen $\mathrm{OH}$, Munck LK. Drug insight: aminosalicylates for the treatment of IBD. Nat Clin Pract Gastroenterol Hepatol. 2007;4:160-70.

28. Kornbluth A, Sachar DB. Ulcerative colitis practice guidelines in adults (update): American College of Gastroenterology, Practice Parameters Committee. Am J Gastroenterol. 2004;99:1371-85.

29. Scholmerich J. Review article: systemic and topical steroids in inflammatory bowel disease. Aliment Pharmacol Ther. 2004;20:66-74.

30. Talley NJ, Abreu MT, Achkar JP, et al. An evidencebased systematic review on medical therapies for inflammatory bowel disease. Am J Gastroenterol. 2011;106(Suppl 1):S2-25. (quiz S26).

31. Jacobstein DA, Mamula P, Markowitz JE, Leonard M, Baldassano RN. Predictors of immunomodulator use as early therapy in pediatric Crohn's disease. J Clin Gastroenterol. 2006;40:145-8.

32. Markowitz J, Grancher K, Kohn N, Lesser M, Daum F. A multicenter trial of 6-mercaptopurine and prednisone in children with newly diagnosed Crohn's disease. Gastroenterology. 2000;119:895-902.

33. Faubion WA Jr, Loftus EV Jr, Harmsen WS, Zinsmeister AR, Sandborn WJ. The natural history of corticosteroid therapy for inflammatory bowel disease: a population-based study. Gastroenterology. 2001;121:255-60.

34. Lichtenstein GR, Abreu MT, Cohen R, Tremaine W. American Gastroenterological Association Institute technical review on corticosteroids, immunomodulators, and infliximab in inflammatory bowel disease. Gastroenterology. 2006;130:940-87.
35. Lichtiger S, Present DH, Kornbluth A, et al. Cyclosporine in severe ulcerative colitis refractory to steroid therapy. $\mathrm{N}$ Engl J Med. 1994;330:1841-5.

36. Van Assche G, D'Haens G, Noman M, et al. Randomized, double-blind comparison of $4 \mathrm{mg} / \mathrm{kg}$ versus $2 \mathrm{mg} / \mathrm{kg}$ intravenous cyclosporine in severe ulcerative colitis. Gastroenterology. 2003;125:1025-31.

37. Ogata H, Matsui T, Nakamura $M$, et al. A randomised dose finding study of oral tacrolimus (FK506) therapy in refractory ulcerative colitis. Gut. 2006;55:1255-62.

38. D'Haens G, Lemmens L, Geboes $\mathrm{K}$, et al. Intravenous cyclosporine versus intravenous corticosteroids as single therapy for severe attacks of ulcerative colitis. Gastroenterology. 2001;120:1323-9.

39. Castro M, Papadatou B, Ceriati E, et al. Role of cyclosporin in preventing or delaying colectomy in children with severe ulcerative colitis. Langenbecks Arch Surg. 2007;392:161-4.

40. Kirschner BS. Safety of azathioprine and 6-mercaptopurine in pediatric patients with inflammatory bowel disease. Gastroenterology. 1998;115:813-21.

41. Kandiel A, Fraser AG, Korelitz BI, Brensinger C, Lewis JD. Increased risk of lymphoma among inflammatory bowel disease patients treated with azathioprine and 6-mercaptopurine. Gut. 2005;54:1121-5.

42. Berg DF, Bahadursingh AM, Kaminski DL, Longo WE. Acute surgical emergencies in inflammatory bowel disease. Am J Surg. 2002;184:45-51.

43. Larson DW, Pemberton JH. Current concepts and controversies in surgery for IBD. Gastroenterology. 2004;126:1611-9.

44. Hueting WE, Buskens E, van der Tweel I, Gooszen HG, van Laarhoven CJ. Results and complications after ileal pouch anal anastomosis: a meta-analysis of 43 observational studies comprising 9,317 patients. Dig Surg. 2005;22:69-79.

45. Ordas I, Mould DR, Feagan BG, Sandborn WJ. AntiTNF monoclonal antibodies in inflammatory bowel disease: pharmacokinetics-based dosing paradigms. Clin Pharmacol Ther. 2012;91:635-46.

46. Knight DM, Trinh $\mathrm{H}$, Le J, et al. Construction and initial characterization of a mouse-human chimeric anti-TNF antibody. Mol Immunol. 1993;30:1443-53. 
47. Kimura K, Takayanagi R, Yokoyama H, Yamada Y. Theory-based analysis of anti-inflammatory effect of infliximab on Crohn's disease and rheumatoid arthritis. Rheumatol Int. 2012;32:145-50.

48. Lugering A, Schmidt M, Lugering N, Pauels HG, Domschke $\mathrm{W}$, Kucharzik $\mathrm{T}$. Infliximab induces apoptosis in monocytes from patients with chronic active Crohn's disease by using a caspasedependent pathway. Gastroenterology. 2001;121: 1145-57.

49. Scallon BJ, Moore MA, Trinh H, Knight DM, Ghrayeb J. Chimeric anti-TNF-alpha monoclonal antibody cA2 binds recombinant transmembrane TNF-alpha and activates immune effector functions. Cytokine. 1995;7:251-9.

50. Rutgeerts P, Sandborn WJ, Feagan BG, et al. Infliximab for induction and maintenance therapy for ulcerative colitis. $N$ Engl J Med. $2005 ; 353: 2462-76$.

51. Ford AC, Sandborn WJ, Khan KJ, Hanauer SB, Talley NJ, Moayyedi P. Efficacy of biological therapies in inflammatory bowel disease: systematic review and meta-analysis. Am J Gastroenterol. 2011;106: 644-59. (quiz 660).

52. Sands BE, Tremaine WJ, Sandborn WJ, et al. Infliximab in the treatment of severe, steroidrefractory ulcerative colitis: a pilot study. Inflamm Bowel Dis. 2001;7:83-8.

53. Probert CS, Hearing SD, Schreiber S, et al. Infliximab in moderately severe glucocorticoid resistant ulcerative colitis: a randomised controlled trial. Gut. 2003;52:998-1002.

54. Jarnerot G, Hertervig E, Friis-Liby I, et al. Infliximab as rescue therapy in severe to moderately severe ulcerative colitis: a randomized, placebo-controlled study. Gastroenterology. 2005;128:1805-11.

55. Serrano MS, Schmidt-Sommerfeld E, Kilbaugh TJ, Brown RF, Udall JN Jr, Mannick EE. Use of infliximab in pediatric patients with inflammatory bowel disease. Ann Pharmacother. 2001;35:823-8.

56. Mamula P, Markowitz JE, Brown KA, Hurd LB, Piccoli DA, Baldassano RN. Infliximab as a novel therapy for pediatric ulcerative colitis. J Pediatr Gastroenterol Nutr. 2002;34:307-11.

57. Mamula P, Markowitz JE, Cohen LJ, von Allmen D, Baldassano RN. Infliximab in pediatric ulcerative colitis: two-year follow-up. J Pediatr Gastroenterol Nutr. 2004;38:298-301.

58. Russell GH, Katz AJ. Infliximab is effective in acute but not chronic childhood ulcerative colitis. J Pediatr Gastroenterol Nutr. 2004;39:166-70.
59. Eidelwein AP, Cuffari C, Abadom V, Oliva-Hemker $M$. Infliximab efficacy in pediatric ulcerative colitis. Inflamm Bowel Dis. 2005;11:213-8.

60. Fanjiang G, Russell GH, Katz AJ. Short- and longterm response to and weaning from infliximab therapy in pediatric ulcerative colitis. J Pediatr Gastroenterol Nutr. 2007;44:312-7.

61. Cucchiara S, Romeo E, Viola F, et al. Infliximab for pediatric ulcerative colitis: a retrospective Italian multicenter study. Dig Liver Dis. 2008;40:S260-4.

62. Tiemi J, Komati S, Sdepanian VL. Effectiveness of infliximab in Brazilian children and adolescents with Crohn disease and ulcerative colitis according to clinical manifestations, activity indices of inflammatory bowel disease, and corticosteroid use. J Pediatr Gastroenterol Nutr. 2010;50:628-33.

63. Hyams JS, Lerer T, Griffiths A, et al. Outcome following infliximab therapy in children with ulcerative colitis. Am J Gastroenterol. 2010;105:1430-6.

64. Hyams J, Damaraju L, Blank M, et al. Induction and maintenance therapy with infliximab for children with moderate to severe ulcerative colitis. Clin Gastroenterol Hepatol. 2012;10(391-9):e1.

65. McGinnis JK, Murray KF. Infliximab for ulcerative colitis in children and adolescents. J Clin Gastroenterol. 2008;42:875-9.

66. Truelove SC, Witts LJ. Cortisone in ulcerative colitis; final report on a therapeutic trial. $\mathrm{Br}$ Med J. 1955;2:1041-8.

67. Turner D, Levine A, Escher JC, et al. Management of Pediatric Ulcerative Colitis: Joint ECCO and ESPGHAN Evidence-based Consensus Guidelines. J Pediatr Gastroenterol Nutr. 2012;55:340-61.

68. Baert F, Noman M, Vermeire S, et al. Influence of immunogenicity on the long-term efficacy of infliximab in Crohn's disease. $\mathrm{N}$ Engl J Med. 2003;348:601-8.

69. Karmiris K, Paintaud G, Noman M, et al. Influence of trough serum levels and immunogenicity on longterm outcome of adalimumab therapy in Crohn's disease. Gastroenterology. 2009;137:1628-40.

70. Seow CH, Newman A, Irwin SP, Steinhart AH, Silverberg MS, Greenberg GR. Trough serum infliximab: a predictive factor of clinical outcome for infliximab treatment in acute ulcerative colitis. Gut. 2010;59:49-54.

71. Maser EA, Villela R, Silverberg MS, Greenberg GR. Association of trough serum infliximab to clinical 
outcome after scheduled maintenance treatment for Crohn's disease. Clin Gastroenterol Hepatol. 2006;4:1248-54.

72. Lichtenstein GR, Rutgeerts P, Sandborn WJ, et al. A pooled analysis of infections, malignancy, and mortality in infliximab- and immunomodulatortreated adult patients with inflammatory bowel disease. Am J Gastroenterol. 2012;107:1051-63.

73. Kolho KL, Ruuska T, Savilahti E. Severe adverse reactions to Infliximab therapy are common in young children with inflammatory bowel disease. Acta Paediatr. 2007;96:128-30.

74. Diak P, Siegel J, La Grenade L, Choi L, Lemery S, McMahon A. Tumor necrosis factor alpha blockers and malignancy in children: forty-eight cases reported to the Food and Drug Administration. Arthritis Rheum. 2012;62:2517-24.

75. Kotlyar DS, Osterman MT, Diamond RH, et al. A systematic review of factors that contribute to hepatosplenic T-cell lymphoma in patients with inflammatory bowel disease. Clin Gastroenterol Hepatol. 2011;9(36-41):e1.

76. Sandborn WJ, van Assche G, Reinisch W, et al. Adalimumab induces and maintains clinical remission in patients with moderate-to-severe ulcerative colitis. Gastroenterology. 2012;142:25765. e1-3.

77. Noe JD, Pfefferkorn M. Short-term response to adalimumab in childhood inflammatory bowel disease. Inflamm Bowel Dis. 2008;14:1683-7.

78. Hyams JS, Griffiths A, Markowitz J, et al. Safety and efficacy of adalimumab for moderate to severe Crohn's disease in children. Gastroenterology. 2012;143(365-74):e2.

79. Rosh JR, Lerer T, Markowitz J, et al. Retrospective Evaluation of the Safety and Effect of Adalimumab Therapy (RESEAT) in pediatric Crohn's disease. Am J Gastroenterol. 2009;104:3042-9. 